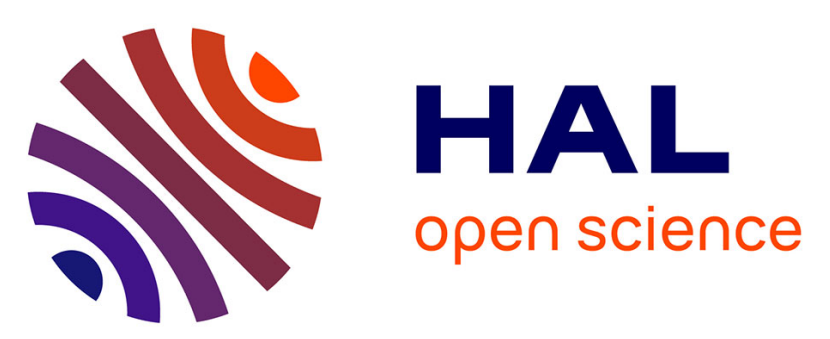

\title{
Intra-species growth-inhibition by is a possible virulence trait in necrotic enteritis in broilers
}

Leen Timbermont, Anouk Lanckriet, Frank Pasmans, Freddy Haesebrouck, Richard Ducatelle, Filip van Immerseel

\section{- To cite this version:}

Leen Timbermont, Anouk Lanckriet, Frank Pasmans, Freddy Haesebrouck, Richard Ducatelle, et al. Intra-species growth-inhibition by is a possible virulence trait in necrotic enteritis in broilers. Veterinary Microbiology, 2009, 137 (3-4), pp.388. 10.1016/j.vetmic.2009.01.017 . hal-00485533

\section{HAL Id: hal-00485533 \\ https://hal.science/hal-00485533}

Submitted on 21 May 2010

HAL is a multi-disciplinary open access archive for the deposit and dissemination of scientific research documents, whether they are published or not. The documents may come from teaching and research institutions in France or abroad, or from public or private research centers.
L'archive ouverte pluridisciplinaire HAL, est destinée au dépôt et à la diffusion de documents scientifiques de niveau recherche, publiés ou non, émanant des établissements d'enseignement et de recherche français ou étrangers, des laboratoires publics ou privés. 


\section{Accepted Manuscript}

Title: Intra-species growth-inhibition by Clostridium perfringens is a possible virulence trait in necrotic enteritis in broilers

Authors: Leen Timbermont, Anouk Lanckriet, Frank Pasmans, Freddy Haesebrouck, Richard Ducatelle, Filip Van Immerseel

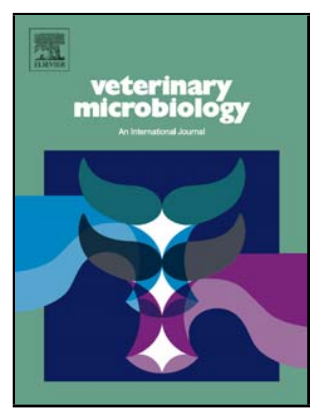

PII: S0378-1135(09)00045-5

DOI: doi:10.1016/j.vetmic.2009.01.017

Reference: VETMIC 4339

To appear in: $\quad$ VETMIC

Received date: $\quad 13-10-2008$

Revised date: $\quad 12-1-2009$

Accepted date: $\quad$ 13-1-2009

Please cite this article as: Timbermont, L., Lanckriet, A., Pasmans, F., Haesebrouck, F., Ducatelle, R., Van Immerseel, F., Intra-species growth-inhibition by Clostridium perfringens is a possible virulence trait in necrotic enteritis in broilers, Veterinary Microbiology (2008), doi:10.1016/j.vetmic.2009.01.017

This is a PDF file of an unedited manuscript that has been accepted for publication. As a service to our customers we are providing this early version of the manuscript. The manuscript will undergo copyediting, typesetting, and review of the resulting proof before it is published in its final form. Please note that during the production process errors may be discovered which could affect the content, and all legal disclaimers that apply to the journal pertain. 
1 Intra-species growth-inhibition by Clostridium perfringens is a possible virulence trait in necrotic enteritis in broilers

3

4 Leen Timbermont*, Anouk Lanckriet, Frank Pasmans, Freddy Haesebrouck, Richard Ducatelle and Filip Van Immerseel

6

7 Department of Pathology, Bacteriology and Avian Diseases, Research Group Veterinary Public

8 Health and Zoonoses, Faculty of Veterinary Medicine, Ghent University, Salisburylaan 133, B9820 Merelbeke, Belgium.

10

11 *Corresponding author. Tel.: +32 9264 7448; fax: +32 92647789

12 E-mail address: leen.timbermont@ugent.be

13

14 


\section{Abstract}

15 Necrotic enteritis in broiler chickens is associated with Clostridium perfringens type A, carrying

16 the NetB toxin. C. perfringens type A is also a member of the normal intestinal microbiota of

17 broilers. Clinically healthy chickens carry several different Clostridium perfringens clones in

18 their intestine. In flocks suffering from necrotic enteritis, however, mostly only one single clone

19 is isolated from the gut of all the diseased animals. Selective proliferation of these clinical

20 outbreak strains in the gut and spread within the flock seems likely, but an explanation has not

21 yet been given. The hypothesis that necrotic enteritis associated Clostridium perfringens strains

22 might suppress the growth of normal microbiota Clostridium perfringens strains, was therefore

23 tested. Twenty-six Clostridium perfringens strains isolated from healthy broilers and 24 clinical

24 outbreak isolates were evaluated for their ability to induce intra-species growth-inhibition in an in

25 vitro setup. A significantly higher proportion of the Clostridium perfringens clinical outbreak

26 strains inhibited the growth of other Clostridium perfringens strains compared to Clostridium

27 perfringens strains isolated from the gut of healthy chickens. It is proposed that, in addition to

28 toxin production, intra-species inhibition may be a virulence trait that contributes to the ability of

29 certain Clostridium perfringens strains to cause necrotic enteritis in broilers.

31 Keywords: Clostridium perfringens / broiler / necrotic enteritis / growth-inhibition 


\section{1. Introduction}

33 Since the ban on growth-promoting antibiotics in animal feed in the European Union,

34 Clostridium (C.) perfringens associated necrotic enteritis is reemerging in broilers (Grave et al.,

35 2004; Van Immerseel et al., 2004; Williams, 2005). Necrotic enteritis in poultry is associated

36 with C. perfringens type A, carrying the NetB toxin (Keyburn et al., 2008; Van Immerseel et al.,

37 2008). C. perfringens type A is also a member of the normal intestinal microbiota of broilers.

38 Strains isolated from healthy broilers, however, do not induce necrotic enteritis in an

39 experimental model using predisposing factors, in contrast to strains isolated from outbreaks of

40 necrotic enteritis (Timbermont et al., 2008).

41 In C. perfringens isolates from healthy birds, a high degree of genetic diversity is found,

42 even between isolates from the same animal. In contrast, different isolates from a flock suffering

43 from a clinical outbreak are generally of the same Pulsed Field Gel Electrophoresis (PFGE) type,

44 regardless of the animal or the part of the intestine from which the strain was isolated (Nauerby et

45 al., 2003; Gholamiandehkordi et al., 2006). The reason for the presence of a single clone in

46 necrotic enteritis outbreaks is not known. It is speculated that during an outbreak, certain

47 C. perfringens strains have a competitive advantage over other C. perfringens strains in the

48 broiler gut.

49 In the present study, strains isolated from healthy broilers and strains isolated from

50 broilers suffering from necrotic enteritis were compared with respect to their capacity of intra-

51 species growth-inhibition in an in vitro inhibition assay.

\section{2. Materials and methods}

54 2.1. Bacteria 
Fifty $C$. perfringens type A strains belonging to different genotypes, as analyzed by

56 PFGE, were included. Thirty-five strains were isolated from broiler chickens in Belgium: 26

57 strains from clinically healthy broiler chickens and 9 strains from broilers suffering from necrotic

58 enteritis (Gholamiandehkordi et al., 2006). Fifteen Danish C. perfringens isolates from necrotic

59 enteritis cases were kindly provided by Dr. L. Bjerrum (Nauerby et al., 2003).

60 Strains of C.perfringens were grown on Colombia agar (Oxoid, Basingstoke, UK)

61 containing $5 \%$ defibrinated sheep blood. Plates were incubated at $37^{\circ} \mathrm{C}$ in an anaerobic working

62 cabinet (invivo ${ }_{2} 500$, Ruskinn Life Sciences, Bridgend, UK), in an atmosphere of

$638 \% \mathrm{H}_{2}: 8 \% \mathrm{CO}_{2}: 84 \% \mathrm{~N}_{2}$. Strains were stored at $-80^{\circ} \mathrm{C}$ in lyophilisation medium (LYM) containing

$647 \%$ glucose, 23\% Brain Heart Infusion broth (BHI, Oxoid) and 70\% defibrinated horse serum

65 (Invitrogen, Merelbeke, Belgium).

\subsection{In vitro growth-inhibition assay}

68 The 50 C. perfringens strains were used in a checkerboard test for intra-species growth-

69 inhibition. Each strain was cultured anaerobically in BHI broth (Oxoid) for $24 \mathrm{~h}$ at $37^{\circ} \mathrm{C}$. The

70 overnight cultures were diluted in Phosphate Buffered Saline (PBS) to a density of McFarland

71 No. 0.5 , and $200 \mu \mathrm{l}$ of these suspensions were spread with a sterile swab on the whole surface of

72 BHI agar plates to obtain a bacterial lawn $(12 \mathrm{~cm} \mathrm{x} 12 \mathrm{~cm})$. A single colony of each

73 C. perfringens isolate was transferred with a sterile toothpick to the agar plates seeded with the

74 different $C$. perfringens strains. Absence of growth of the bacterial lawn around a colony results

75 in an inhibition zone (Fig. 1). After overnight incubation under anaerobic conditions, diameters

76 of inhibition zones were measured in $\mathrm{mm}$. The tests were performed in triplicate.

\subsection{Statistical analysis}


The data were analysed with SPSS 16 software using the chi-square test to compare the number of strains of the normal microbiota group with number of strains of the necrotic enteritis

81 group that were able to inhibit other strains. The student t-test was used to compare the mean 82 inhibition zones of the healthy animal strains and the necrotic enteritis strains. Significance was 83 determined at $\mathrm{P}<0.05$.

\section{Results}

Sixty percent of all tested strains inhibited growth of at least one other strain of C. perfringens (i.e., there was a zone of clearing around the stabbed colony). While some strains inhibited growth of many other strains, others had a very limited inhibitory spectrum. Fifteen $(58 \%)$ of the 26 healthy animal strains and $4(17 \%)$ of the 24 clinical outbreak strains were not able to inhibit the growth of any other strain. In contrast, $46 \%(11 / 24)$ of the clinical outbreak strains were able to inhibit more than $90 \%$ (more than $45 / 50$ ) of the other strains while this was only the case for $15 \%(4 / 26)$ of the healthy animal strains (Fig. 2). The number of strains that were able to inhibit any number of other strains was significantly higher for the clinical outbreak strains than for the healthy animal strains $(\mathrm{P}<0.05)$. If strains were able to inhibit the growth of other $C$. perfringens strains, they were able to inhibit both healthy animal strains and necrotic enteritis outbreak strains.

In the strains that were able to inhibit, the zones of inhibition varied for the strains from healthy broilers between $3 \mathrm{~mm}$ and $7 \mathrm{~mm}$ and for the necrotic enteritis strains between $3.5 \mathrm{~mm}$ and $5.5 \mathrm{~mm}$. There was no significant difference in the average sizes of the inhibition zones: 4.9 $\mathrm{mm}$ and $4.3 \mathrm{~mm}$ for healthy animal strains and clinical outbreak strains, respectively.

\section{Discussion}


104 C. perfringens in a broiler flock suffering from necrotic enteritis. Our results show that inhibition

105 of other $C$. perfringens strains is a trait that is significantly more developed in clinical outbreak

106 strains, compared with healthy animal strains. A minority of healthy animal strains were able to

107 inhibit other $C$. perfringens strains isolated from healthy birds and necrotic enteritis strains. In a

108 recent study of Barbara et al. (2008), none of the normal flora strains $(n=17)$ could inhibit the

109 growth of other $C$. perfringens strains. Also a minority of necrotic enteritis outbreak strains did

110 not have the intra-species growth-inhibitory phenotype. Possibly in these strains other virulence

111 traits may compensate for the lack of inhibitory capacity. Another possible explanation for the

112 lack of in vitro inhibitory phenotype is that expression of the gene encoding for the growth-

113 inhibiting phenomenon can be down-regulated by certain signal transduction systems or

114 regulators (Dupuy and Mamouros, 2006). The gene for the growth-inhibiting factor might also be

115 located on a plasmid and the absence of growth-inhibition may be caused by the loss of this

116 plasmid after in vitro cultivation (Rood and Cole, 1991).

117 The results of the radial diffusion assay suggest that the intra-species inter-strain growth-

118 inhibition is caused by a substance secreted by the bacterium into its micro-environment. The

119 nature of this substance is hitherto unclear. It is known that $C$. perfringens is able to produce

120 bacteriocins capable of lysing other $C$. perfringens strains. Watson et al. (1982) observed that

$12179 \%$ of strains implicated in food poisoning outbreaks produced bacteriocins; however, only $18 \%$

122 of 322 isolates from the feces of healthy persons, human and animal infections, various foods,

123 and the environment produced bacteriocins suggesting a relationship between bacteriocin

124 production and the ability to cause food poisoning.

125 In this study, secretion of intra-species growth-inhibitory substances by C. perfringens is 126 proposed to be an additional virulence trait that can possibly contribute to the pathogenesis of 
127 necrotic enteritis by selective proliferation of one single clone in the broiler gut. Indeed, when

128 certain environmental predisposing factors, such as a coccidial infection, are present, nutrients

129 utilizable by $C$. perfringens are leaking in the lumen (Collier et al., 2008). Intra-species inter-

130 strain growth inhibition may constitute an important advantage for certain strains in the

131 competition for nutrients in the intestinal tract. It is well documented that $C$. perfringens requires

132 at least 11 different essential amino acids for its multiplication (Petit et al., 1999). Suppressing its

133 competitors may allow unlimited access to the nutrients and thus the possibility of explosive

134 multiplication. The massive production of specific toxins and enzymes, such as the NetB toxin

135 and proteolytic enzymes (Olkowski et al., 2006; Olkowski et al., 2008; Keyburn et al., 2008) at

136 sites of multiplication of these bacteria in the gut would then lead to necrotic lesions, and thus the

137 release of more nutrients, completing the cycle.

138 In conclusion, $C$. perfringens outbreak isolates are significantly more capable of intra-

139 species growth inhibition compared to strains isolated from healthy birds. It is proposed that

140 intra-species growth-inhibition by $C$. perfringens is a possible virulence trait in necrotic enteritis

141 in broilers.

\section{Acknowledgements}

144 We would like to thank Veerle Flama for her skilful technical assistance. Dr. L. Bjerrum is

145 acknowledged for providing strains. This work was supported by the Institute for Science and

146 Technology, Flanders (IWT). F. Van Immerseel is supported by a Postdoctoral Research Grant of

147 the Research Foundation - Flanders (FWO) and by the Research Fund of Ghent University 148 (BOF).

149 


\section{References}

150 Barbara, A.J., Trinh, H.T., Glock, R.D., Songer, J.G., 2008. Necrotic enteritis-producing strains of Clostridium perfringens displace non-necrotic enteritis strains from the gut of chicks. Vet. Microbiol. 126, 377-382.

Dupuy, B., Matamouros, S., 2006. Regulation of toxin and bacteriocin synthesis in Clostridium species by a new subgroup of RNA polymerase $\sigma$-factors. Res. Microbiol. 157, 201-205.

Collier, C.T., Hofacre, C.L., Payne, A.M., Anderson, D.B., Kaiser, P. Mackie, R.I., Gaskins, H.R., 2008. Coccidia-inuced mucogenesis promotes the onset of necrotic enteritis by supporting Clostridium perfringens growth. Vet. Immunol. Immunopathol., 122, 105-114.

Gholamiandehkordi, A.R., Ducatelle, R., Heyndrickx, M., Haesebrouck, F., Van Immerseel, F., 2006. Molecular and phenotypical characterization of Clostridium perfringens isolates from poultry flocks with different disease status. Vet. Microbiol. 113, 143-152.

Grave, K., Kaldhusdal, M.C., Kruse, H., Harr, L.M., Flatlandsmo, K., 2004. What has happened in Norway after the ban of avoparcin? Consumption of antimicrobials by poultry. Prev. Vet. Med. 62, 59-72.

Keyburn, A.L., Boyce, J.D., Vaz, P., Bannam, T.L., Ford, M.E., Parker, D., Di Rubbo, A., Rood, J.I., Moore, R.J., 2008. NetB, a new toxin that is associated with avian necrotic enteritis caused by Clostridium perfringens. PLoS Pathog. 4(2): e26. doi:10.1371/journal.ppat.0040026.

Nauerby, B., Pedersen, K., Madsen, M., 2003. Analysis by pulsed-field gel electrophoresis of the genetic diversity among Clostridium perfringens isolates from chickens. Vet. Microbiol. 94, 257-266.

Olkowski, A.A., Wojnarowicz, C., Chirino-Trejo, Drew, M.D. 2006. Responses of broiler chickens orally challenged with Clostridium perfringens isolated from field cases of necrotic enteritis. Res. Vet. Sci., 8, 99-108.

Olkowski, A.A., Wojnarowicz, C., Chirino-Trejo, M., Laarveld, B., Sawicki, G., 2008. Subclinical necrotic enteritis in broiler chickens: Novel etiological consideration based on ultra-structural and molecular changes in the intestinal tissue. Res. Vet. Sci., 85, 543-553.

Petit, L., Gibert, M., Popoff, M.R., 1999. Clostridium perfringens: toxinotypes and genotype. Trends in Microbiology, 7, 104-110. 
179 Rood, J.I., Cole, S.T., 1991. Molecular genetics and pathogenesis of Clostridium perfringens. 180 Microbiol. rev., 55, 621-648.

181 Timbermont, L., Lanckriet, A., Gholamiandehkordi A.R., Pasmans, F., Martel, A., Haesebrouck, F., Ducatelle, R., Van Immerseel, F., 2008. Origin of Clostridium perfringens isolates determines the ability to induce necrotic enteritis in broilers. Comp. Immunol. Microbiol. Infect. Dis. doi: 10.1016/j.cimid.2008.07.001.

Van Immerseel, F., De Buck, J., Pasmans, F., Huyghebaert, G., Haesebrouck, F., Ducatelle, R., 2004. Clostridium perfringens in poultry: an emerging threat for animal and public health. Avian Pathol. 33, 537-549.

Van Immerseel, F., Rood, J.I., Moore, R.J., Titball, R.W., 2008. Rethinking our understanding of the pathogenesis of necrotic enteritis in chickens. Trends Microbiol. Doi: 10.1016/j.tim.2008.09.005.

Watson, G.N., Stringer, M.F., Gilbert, R.J., Mahony, D.E., 1982. The potential of bacteriocin typing in the study of Clostridium perfringens food poisoning. J. Clin. Pathol., 35, 13611365.

Williams, R.B., 2005. Intercurrent coccidiosis and necrotic enteritis of chickens: rational, integrated disease management by maintenance of gut integrity. Avian Pathol. 34, 159180. 


\section{Figure 1}

198 Result of the radial diffusion assay. A colony of a $C$. perfringens isolate was stabbed through a

199 lawn of another C. perfringens strain and partially through the agar beneath. A. No inhibition B.

200 Clear inhibition zone

201

202

$203 \quad$ Figure 2

204 Percentage of $C$. perfringens strains secreting intra-species inhibitory substances. The percentage

205 of healthy animal strains (grey) and clinical outbreak strains (black) of $C$. perfringens that were 206 able to inhibit a number of $C$. perfringens strains $(\mathrm{N}=50)$, as indicated on the $\mathrm{X}$-axis, is shown. 


\section{Figure $1 \mathrm{~A}$}

\section{A}

\section{$2 \mathrm{~mm}$}

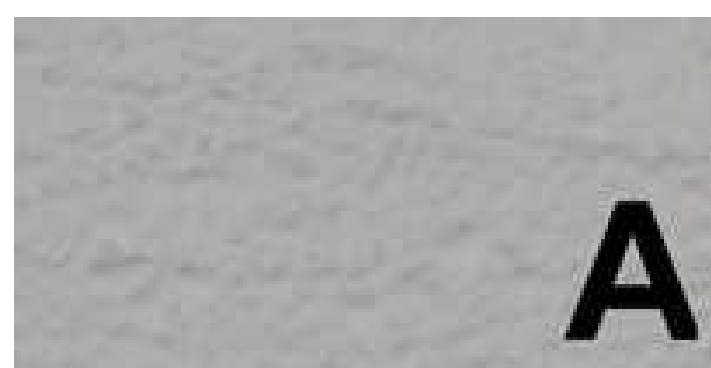




\section{B}

\section{$2 \mathrm{~mm}$}




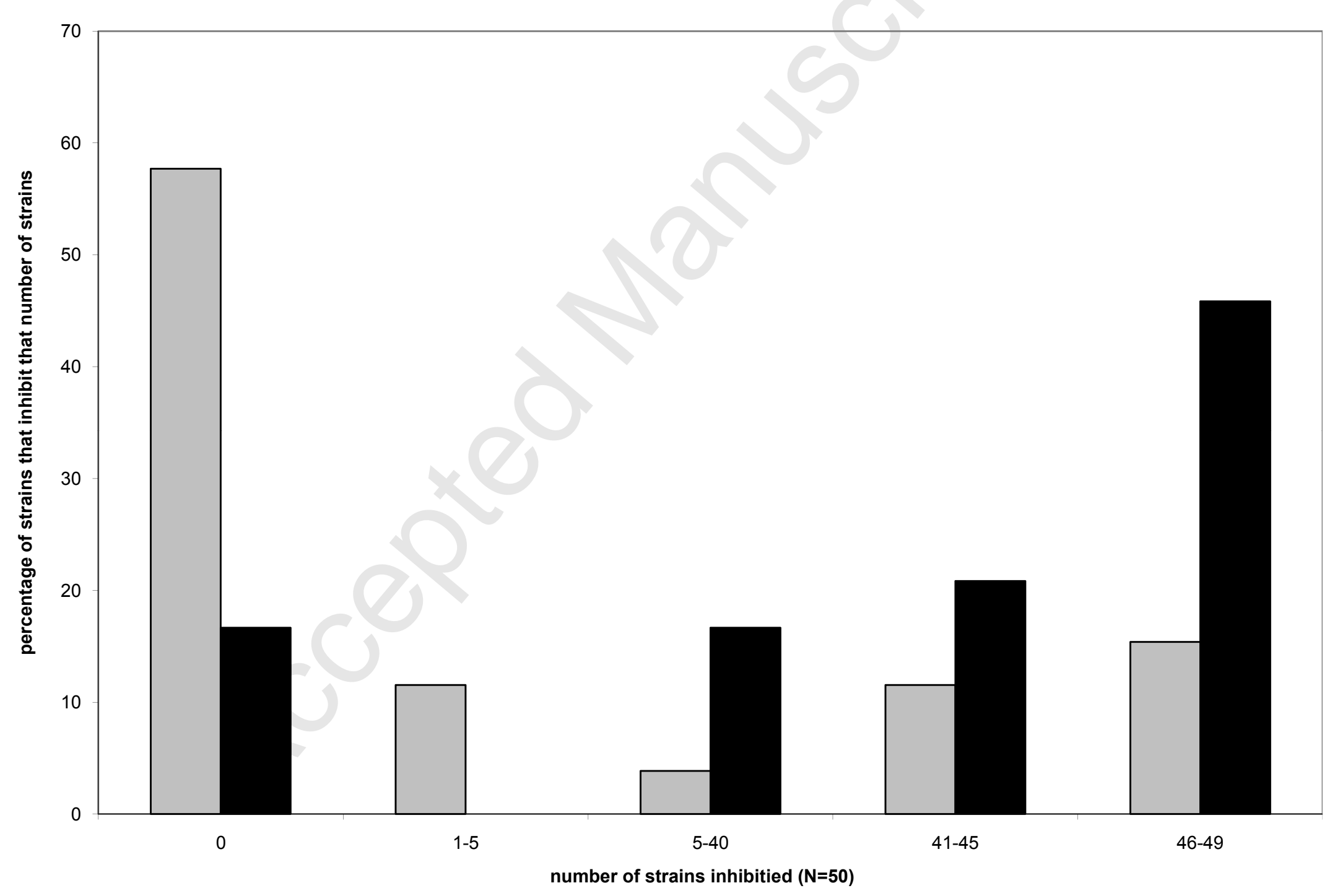

